\title{
O grotesco em Meierhold: princípios para a criação de uma nova teatralidade
}

Marisa Naspolini*

A noção de grotesco se encontra em quase todas as vanguardas artísticas do começo do século XX. Da literatura às artes plásticas, o termo é comumente relacionado ao exagero, à caricatura, ao satírico ou ao fantástico. Sua origem está fortemente ligada ao elemento pictórico, como os ornamentos murais antigos redescobertos no Renascimento, que mesclam formas do reino vegetal a corpos humanos ou de animais, reforçando a relação estreita com a imagem, o insólito e o artificial.

Bakhtin (2002) relacionou o grotesco à cultura cômica popular. Para ele, o conceito surge em períodos de transição ou de crise, em que a ordem antiga é questionada sem que um novo sistema a tenha substituído. No seu entendimento, há uma tendência de reducionismo no uso do termo, principalmente por parte de esteticistas alemães e russos. Ao se referir à análise do pesquisador alemão Schneegans da obra de Rabelais, reprova sua ignorância em relação à "ambivalência profunda e essencial" (BAKHTIN 2002:265) do grotesco, que estaria reduzido à idéia de profusão, hiperbolismo e excesso, configurando-se ora como gênero cômico, ora como trágico.

Para o teórico russo, a especificidade do grotesco consiste justamente em unir trágico e cômico ao mesmo tempo, tendo o corpo humano, e seus limites com o mundo que o cerca, como base da concepção de seu aspecto imagético. Trata-se de um corpo em movimento, que jamais está pronto ou acabado, mas encontra-se eternamente em processo de construção.

Meierhold dá ao termo uma interpretação pessoal. Conceito-chave de sua obra, o grotesco meyerholdiano não se reduz a uma figura de estilo, exagero, hipérbole, mas integra as diversas contradições sobre as quais funciona seu modo de criação: observação minuciosa e seleção rigorosa, fragmento e generalização, realismo e convenção, política e estética, teatro

*Marisa Naspolini é especialista em Análise do Movimento pelo Laban/Bartenieff Institute of Movement Studies de Nova York e mestranda em Teatro na UDESC. Professora do Departamento de Artes Cênicas da UDESC. 
de variedades e drama musical. A unidade de sua obra baseia-se na união destes contrários e na tensão gerada por esta união.

O grotesco não é um elemento de contraste, mas a estrutura contrastante em si, movimento que liga duas imagens inversas, cômico e trágico ao mesmo tempo, denominador comum a todas as formas teatrais que aguçam a curiosidade do encenador russo. Meierhold vincula sua reflexão sobre o grotesco ao desejo de aproximação de um grande público popular, criando um mundo palpitante, em transformação permanente. Ao mesmo tempo em que este conceito operaria como visão particular de mundo e de teatro, o grotesco funciona como um método de articulação da encenação e do jogo dos duplos conflitivos. Este sistema de contrastes torna-se plenamente visível na montagem de $O$ Inspetor Geral, de Gógol, onde sua visão do grotesco cênico se evidencia através das pantomimas e marionetes, que reforçam a ficção e o jogo das máscaras, fundado na dualidade do tragicômico.

A duplicidade presente na vida do artista, que se alterna constantemente entre o pessimismo suicida e o otimismo farsesco, erudito amante dos livros e obcecado pelos exercícios físicos, revela o que ele próprio define como a essência da teatralidade. O grotesco - duplo de estética e método - permite a destruição da continuidade no nível da narrativa ou da psicologia, provocando fenômenos de ruptura, e abre espaço para a instalação de uma nova ordem calcada na construção de materiais e temas que dialogam através do choque e da relação entre opostos.

Meierhold foi um homem em conflito permanente, consigo mesmo e com sua prática, levando ao extremo a autocrítica desenvolvida, que se refletia em sua obra espetacular. "Eu adoro as situações passionais no teatro e as construo na minha vida"1. Neste movimento permanente de criação/destruição, o inacabado encontra seu lugar de destaque. Em sua busca pela perfeição, Meierhold não concebe o definitivo.

Numa espécie de revolta pessoal contra a realidade, o diretor russo se incumbe da tarefa de transformar o teatro, acreditando que este pode contaminar o espírito de seu tempo, se "aqueles que servem à cena" tomarem consciência de sua missão, liberando-o da reprodução cotidiana e suas fidelidades miméticas, submetendo-o somente a suas próprias leis: "Eu gostaria que todos aqueles que servem à cena tomassem consciência de sua grande missão. (...) Sim, o teatro pode desempenhar um papel enorme na reorganização de tudo o que existe" (PICON-VALLIN 1990:18)².

Para ele, a adoção do grotesco, princípio experimentado anteriormente em várias de suas montagens, é a solução para a crise do teatro. Ao alterar 
a percepção do espectador, tirando-o do plano do conhecido e esperado e instalando-o em outro, que ele não imaginava, Meierhold provoca um deslocamento constante, jogando com contradições agudas e gerando uma espécie de surpresa no público.

\section{Artificialidade e dualidade do corpo grotesco}

$\mathrm{Na}$ construção de sua linguagem cênica, Meierhold elege o corpo do ator como o local onde o grotesco se instala e ganha visibilidade. Seu corpo deve se transformar em obra de arte, assim como a música e o cenário. Abandonando a supremacia do texto literário, o encenador busca a comunicação efetiva do significado na cena através do dinamismo corporal do intérprete. Em direção contrária à busca de um corpo natural, inspirado no modelo grego enaltecido por Isadora Duncan, Meierhold procura construir um corpo artificial, inspirado no ator oriental e no acrobata. Este corpo encontra sua liberdade na disciplina muscular e na organização do pensamento, que permitem o domínio do gesto caótico natural. Levado ao extremo, o ator se transformaria em marionete.

No início do século $X X$, período em que o corpo é revigorado por uma paixão renascente pelo esporte e pelas competições olímpicas, o ator vê seu status transformado. O treinamento a que é submetido visa, sobretudo, aprimorar sua capacidade de reagir prontamente, desenvolver sua orientação espacial e domínio do movimento e aprender a gerar motivações "teatrais" e não psicológicas. O jogo teatral define-se como a arte de combinar livremente um saber técnico corporal acumulado.

O ator também está submetido à dualidade própria da obra meyerholdiana. Influenciado pelas teorias de Constant-Benoit Coquelin, que acreditava em uma "personalidade dual" (KUBIK 2002:4-5) do ator, Meyerhold se refere a um primeiro self, constituído por aquele que atua (the player), e a um segundo, constituído pelo instrumento (the instrument). Esta idéia ganha concretude na fórmula $N=A_{1}+A_{2}$, onde $N$ é o ator formado por dois selves: $A_{1}$ é o primeiro, representando o ator metafísico (que concebe a idéia) e $A_{2}$ é o ator físico (o que executa a idéia). Enquanto os músculos do ator metafísico seriam trabalhados através de um processo de auto-descoberta e uso da imaginação, a musculatura do ator físico demanda um trabalho mais consciente, através de intenso treinamento corporal.

A prática da biomecânica, que envolve uma série de habilidades físicas, incluindo elementos da dança, pantomima, ginástica, malabarismo, acroba- 
cia e música, visa melhorar a independência expressiva de diferentes partes do corpo, aprimorando no ator o seu uso do corpo de forma não cotidiana.

Uma sólida consciência do uso da gravidade e equilíbrio do corpo, aliada ao treinamento do reflexo, da prontidão e da criação de memória muscular, garante a este "ator-maquinista" um domínio eficiente de sua "máquina", cuja relação corpo-mente deve ser harmônica, garantindo que o corpo possa expressar em movimento tudo o que é possível entender mentalmente.

Este corpo dinâmico, ágil, ritmado, é fundamental para incorporar as tensões e conflitos que se evidenciam em movimentos angulosos e exagerados. Na ambição deste novo teatro, o espetáculo está centrado na figura do comediante, misto de ator, cantor, dançarino, malabarista, acrobata, escultor de seu próprio corpo. Novamente no exercício do duplo, Meierhold se inspira de um lado no ator japonês, exótico e refinado, cuja gestualidade se aproxima da dança, e, de outro, no universo popular, origem do clown, do circo, do petrushka (teatro de marionetes russo) e do comediante dell'arte. Mas é preciso formar este novo ator.

\section{O Corno Magnífico: grotesco, commedia italiana e objetos animados}

Na montagem deste espetáculo dedicado a Molière, em 1922, Meierhold exibe abertamente seu jogo tragicômico, construído sobre tensões entre realidade e ficção, insólito e trivial, ação e forma, onde o ator combina diferentes materiais e cria um sistema de personagens, com forte inspiração na Commedia dell'Arte.

O espetáculo é concebido a partir das variantes francesas da Commedia, apostando na sucessão alternada de números diferentes e em combinações de ações precisas e repertorizadas. O número de atores em cena também é fator primordial na construção de dramaticidade (o número ímpar implica em conflito, tensão; o número par induz a uma complicação ou desaceleração da cena, ou ainda à existência de intriga paralela).

A Commedia é vista como meio, não como fim. Diretor e atores estudam roteiros e analisam a variação de certos elementos de base, buscando trabalhar os mesmos personagens em diferentes situações. Por concentrar os vários elementos das artes cênicas, o trabalho com a Commedia permite alimentar uma prática imediata, através da composição de novos roteiros, encenações variadas e manipulação de objetos de forte cunho teatral, além de propiciar um estudo teórico da história e das tradições teatrais. 
Meierhold exige um manuseio hábil e respeitoso dos acessórios. Sua referência é novamente oriental. Ao treinar seus atores a manipular os objetos cênicos, transforma-os em centro da ação dramática. O objeto escapa de sua função cotidiana e torna-se parceiro do ator, tornando-se determinante na movimentação que aquele exibe em cena. Além de auxiliar na definição de caráter e situação social das personagens, os objetos funcionam como ponto de apoio ao jogo, constituindo cadeias biomecânicas de ação e reação entre os atores e entre atores e objetos, revelando seu próprio caráter duplo - ao mesmo tempo em que definem características da personagem, evidenciam as habilidades do intérprete, reforçando a teatralidade (ou a não cotidianidade) da ação. A poética de distanciamento entre a quantidade de energia dispensada pelo ator e o objetivo da tarefa realizada na cena ajuda a compor o tom grotesco nesta relação objetal.

Ao fazer um movimento de retorno às origens, resgatando formas de teatro popular, Meierhold, dá vazão à sua necessidade de reencontrar vínculos com as tradições teatrais. A Commedia dell'arte, assim como o teatro de feira, é representante dos gêneros que fazem da descontinuidade (ou da fragmentação) a essência da cena, elemento fundamental na criação de seu teatro do futuro. O comediante dell'arte, alegre, ágil e improvisador, ícone de sua utopia nos anos 10, torna-se o embrião do ator eficaz, preciso e rigoroso que encarna o ideal taylorista dos anos 20. Em ambos os casos, o jogo é preciso, ritmado, geometrizado. O roteiro denominado $A$ Caça, integrante do repertório da Commedia, é destituído de seu caráter anedótico e, restituída sua essência, transforma-se no exercício Disparando o arco, utilizado amplamente no treinamento biomecânico dos atores.

\section{Dissonância, contraponto e polifonia}

A música tem importância definitiva na encenação meierholdiana, contribuindo tanto para a precisão milimétrica do jogo (no que diz respeito ao ritmo e à métrica) quanto para a construção de dissonância, princípio constitutivo de toda organização musical, que reforça seu modelo de teatro da descontinuidade. Indeciso na infância entre a carreira de violinista e a vida no teatro, Meierhold opta por tornar a música um elemento onipresente em sua criação, principalmente a composição clássica russa e alemã.

Durante a montagem de O Inspetor Geral, em 1926, Meyerhold chama a atenção de seus alunos para o papel primordial da música na sua concepção de grotesco, particularmente no que diz respeito à noção de metamorfose na cena:

"A música é a arte mais perfeita. Ao ouvir uma sinfonia, não esque- 
çam do teatro. A alternância dos contrastes, dos ritmos, dos tempos, a união do tema principal e dos temas secundários, tudo isto é tão necessário no teatro quanto na música" (PICON -VALLIN 1990:338 $)^{3}$.

O espetáculo trabalha com uma idéia de orquestração, tanto visual quanto sonora, uma organização tal dos elementos de cena (ator, luz, movimento e objetos) que gera uma composição explosiva, na qual a transformação, a metamorfose, aparece como característica primordial de linguagem, distanciando-se de uma eventual vulgarização do grotesco e aproximando-se de uma idéia de carnavalização, introduzida através do vocabulário da rua, da mascarada e das artes populares.

Inicialmente, as idéias musicais de Meierhold mantiveram diálogo constante com as pesquisas desenvolvidas por Jaques-Dalcroze e Isadora Duncan, calcadas na simetria e na concordância rítmica. Nas aulas que ministra em seu estúdio, de 1913 a 1917, conduzidas não mais a partir da prática operística, mas de um estudo dos scenarii da Commedia dell'arte, a música é concebida como "uma corrente que acompanha os deslocamentos do ator sobre o espaço cênico e os momentos estáticos de seu jogo" (PICONVALLIN 1989:03) e sua pesquisa se apóia sobre o uso da música na dança de Duncan e Füller e nos estudos de Dalcroze, assim como sua utilização no circo, nas variedades e no teatro oriental. Mas, a partir de 1917, ele passa a recusar a aplicação das teorias de Dalcroze ao teatro e rechaça a dança de Duncan, que qualifica de tediosa e repetitiva, inaugurando um novo tipo de relação entre música e movimento, no qual cada um reina em seu respectivo plano, recusando sua coincidência e submissão à métrica. Está dado o primeiro passo para a formulação de sua teoria do contraponto, que passa a fundamentar as leis cênicas do movimento do ator no tempo e no espaço.

A teoria do contraponto encontra aplicação em vários de seus espetáculos, nos quais a música atua não como fundo musical, mas como uma

"grade de interpretação de uma dramaturgia, um ponto de apoio para a composição cênica, um meio de triunfar sobre o naturalismo, uma vez que ela coloca em cena um ritmo que rompe com o mundo do cotidiano" (PICON-VALLIN, 1989:2) .

Meierhold aposta na criação de dois tecidos paralelos, um cênico e outro musical, que não coincidem, mas constroem conjuntamente uma rede rítmica, polifônica, com desenho claro e plástico, baseado na economia de movimentos, que propicia um diálogo no qual a cena nunca ilustra a música, mas a revela e completa. 
Esta prática evidencia a reivindicação da mise en scène meierholdiana de "deixar à imaginação do espectador a liberdade de completar o que não foi dito" (GUINSBURG 2001:59), idéia tão cara ao drama simbolista. O mínimo de ação permitiria o máximo de tensão, sugerida no desenho plástico do corpo da personagem, que permite "o mergulho do espectador na intimidade do drama" (idem).

Enquanto operador essencial de uma nova teatralidade, o grotesco supera o esquematismo fácil da estilização e busca uma representação plena da existência humana, contraditória, dionisíaca, mas sobretudo avessa a maneirismos e acúmulo de detalhes, ao sentimentalismo e a sutilezas psicológicas. O sentido físico que emana desta fonte energética, irradiante de ação, presente na configuração grotesca em Meierhold, encontra no próprio artista sua principal referência. Sua alma inquieta é a tradução mais fiel do conceito que o norteia. São suas as palavras, numa alusão à montagem de

A Barraca de Feira: "O grotesco busca o supranatural, sintetiza a quintessência dos contrários, cria a imagem do fenômeno. Assim, impele o espectador a tentar decifrar o enigma do inconcebível" (GUINSBURG 2001:63). Meierhold vê nele um recurso "capaz de propiciar uma nova epifania do belo".

Para Guinsburg, o conceito de grotesco que ele propõe em 1911, e que impõe no ano seguinte, parece capaz de fornecer a perspectiva menos redutiva de sua obra, abrindo-Ihe uma possibilidade de análise mais aprofundada. Ao estruturar toda sua obra teatral, o grotesco permite um novo olhar sobre o cotidiano. Unindo fantástico e real, sonho e realidade, Meyerhold organiza de forma teatral suas próprias contradições e as de sua época. A nova ordem imposta pelo corpo tragicômico de seu ator e sua imagem em movimento na cena aponta para um modelo expressivo que revoluciona o contexto teatral, indo além do espaço cênico e refletindo-se na própria reorganização do edifício teatral e das relações na sociedade do início do século XX.

Ao contrapor-se à estética do belo, abrindo espaço para a consciência da relatividade e da dialética, o grotesco se afirma como forma de expressão provocativa que atravessa os séculos. Seu papel na arte tem sido sobretudo o de "firmar a existência das coisas, criticando-as" (PAVIS 2003:189). Neste sentido, podemos pensar seu lugar na produção artística atual. Ao localizar e buscar compreender o homem tragicômico contemporâneo, o grotesco possibilita também sua transformação permanente. A idéia de inacabado e mutante, própria desta estrutura que encerra o contraste em si mesma, coloca o grotesco num lugar específico - não como peça de museu ou referência 
histórica, mas como um conceito vivo que pode traduzir as questões de seu tempo, este tempo.

\section{Notas}

${ }^{1}$ No original: "J'aime les situations passionnées au theatre et je m'en construis dans la vie" (PICON-VALLIN 1990:17).

${ }^{2}$ No original: "Je voudrais flamber de l'esprit de mon temps. Je voudrais que tous ceux qui servent la scène prennent conscience de leur grande mission. (...) Oui, le théâtre, peut jouer um rôle enorme dans la réorganization de tout ce qui existe". (PV 18).

${ }^{3}$ Entrevista com estudantes, realizada em junho de 1938, in Artigos, Cartas, Discursos, Entrevistas. Moscou: Iskousstvo, 1968, tomo II, p. 506.

${ }^{4} \mathrm{~A}$ citação é uma referência à utilização de uma sinfonia de Tchaikovski na montagem de "O Jardim de Cerejeiras", de Tchekhov, em 1914. Tradução de Roberto Mallet.

\section{Bibliografia}

BAKHTIN, Mikhail. A cultura popular na Idade Média e no Renascimento: o contexto de François Rabelais. SP: Hucitec e Annablume, 2002.

CAVALIERE, Arlete. O Inspetor Geral de Gogol / Meyerhold. SP: Perspectiva, 1996.

CRUCIANI, Fabrizio e FALLETTI, Clélia (org.). Meyerhold e la regia di "Le Cocu magnifique" e II montaggio e l'attore in Civiltà Teatrale nel XX Secolo. Bologna: II Mulino, 1986.

GUINSBURG, Jacó. Stanislávski, Meierhold \& Cia. SP: Perspectiva, 2001.

KUBIK, Marianne. Biomechanics: understanding Meyerhold's system of actor training in Movement for actors (org. Nicolle Potter). NY: Allworth Press, 2002.

MEYERHOLD, Vsevolod. Textos teóricos. Madrid: ADEE, 1992. PAVIS, Patrice. Dicionário de Teatro. SP: Perspectiva, 2003. PICON-VALLIN, Béatrice. Meyerhold - Les Voies de la Création Théâtrale. Paris: Éditions du Centre National de la Recherche Scientifique, 1990.

PICON-VALLIN, Béatrice. A música no jogo do ator meyerholdiano in In Le jeu de l'acteur chez Meyerhold et Vakhtangov. Paris: Laboratoires d'études théâtrales de l'Université de Haute Bretagne, 1989. Tradução de Roberto Mallet. 